hydration, as recommended by WHO/UNICEF. The consequences of treatment with high sodium solution might already have set in before adequate free water was available. (b) Sodium to potassium ratio in the standard solution was higher than the low sodium solution which also might contribute to hypernatraemia (discussed in our article).

Although periorbital oedema is a less dangerous complication than hypernatraemia, nevertheless, it reflects sodium retention, albeit isotonic. It is possible, that in these circumstances, excessive renal or extrarenal losses of water in a child with immature renal function may produce hypernatraemia resulting from a disparity between sodium and water content. Further, it has been implied that the judgement of periorbital oedema raises a question of bias, but Dr Hirschhorn will be happy to know that the finding was verified by one of the investigators (S.P.K.), who is a senior consultant to the department of paediatrics and who did not know the groupings.

Dilip Mahalanabis, Asok Chatterjee, and K. N. Jalan Kothari Centre of Gastroenterology, The Calcutta Medical Research Institute, 7/2 Diamond Harbour Road, Calcutta 700027, India

\section{A notable case of nephrosis}

Sir,

The notable, and delightfully retold, case history of a distinguished paediatrician's childhood nephrosis (Archives, 1978, 53, 363) raises some fascinating issues, including the problem of whether it was the pneumococcal peritonitis or the measles that produced remission and cure.

The boy was in a severe relapse until an inappropriate paracentesis resulted in peritonitis. Remission seems to have occurred shortly after the intra-abdominal abscess discharged itself and to have continued during the subsequent measles. Therefore it really does sound as if the peritonitis was the most important agent. Janeway et al. (1948) described the chronology of diuresis after measles. During the initial febrile illness the proteinuria increased and the nephrotic syndrome became worse, but diuresis began at any time from the appearance of the rash to 8 days later. It seems to be unusual for pneumococcal peritonitis to produce remission and cure. The few cases of such peritonitis that I have seen have been disastrous, 2 producing acute renal failure necessitating dialysis and 2 almost killing the children without producing remission. For that reason we ought to follow Sir Frederic Still's policy of discouraging the onset of pneumococcal peritonitis in any child with nephrotic syndrome. All he could do was to advise against paracentesis. We are luckier and can give a daily prophylactic dose of penicillin $\mathrm{V}$ to any nephrotic child who is in relapse and is oedematous.

S. R. MEadow

Department of Paediatrics and Child Health, 27 Blundell Street, Leeds LS1 3ET

\section{Reference}

Janeway, C. A., Moll, G. H., Armstrong, S. H., Jr, Wallace, W. M., Hallman, N., and Barness, L. A. (1948). Diuresis in children with nephrosis; comparison of response to infection of normal serum albumin and to infection, particularly measles. Transactions of the Association of American Physicians, 61, 108-111.

\section{Research involving children-ethics, the law, and the climate of opinion}

Sir,

There is one point, and one only, in your timely and wise Editorial (Archives, 1978, 53, 441) that I wish to question. You say you 'will not accept papers reporting studies where ionising radiations ( $x$-rays or radioisotopes) have been given to normal children for study purposes only'. However, you quote with approval Professor Dworkin's opinion that research may be justifiable provided the risk to the subjects is 'either absent or negligible', p. 441 (his words being 'absent or minimal', p. 445).

In research on the normal variations of growth, particularly at puberty, establishing the subject's physical maturity is in many contexts (endocrine, etc.) extremely important. This is best done by an $x$-ray of the hand and wrist, leading to a 'bone-age' determination. In the past I and my collaborators (supported by the then Ministry of Health) made such studies and in the growth disorder clinic bone-age is a routine tool of prime importance. But some 10 years ago we were dissuaded (by the usual powerful argument) from continuing this part of our study of normal children.

The dose of $x$-rays is 4 millirads, given to an area in which no active bone marrow is believed to exist after age 2 . This dose is the same as the child would get to his whole body should he risk 10 days' skiing at 3000 metres, since irradiation increases with altitude. In a few flights across the Atlantic 4 millirads is absorbed. Is not the risk 'negligible' or 'minimal'?

J. M. TANNER Department of Growth and Development, Institute of Child Health, 30 Guilford Street, London WCIN 1EH

\section{Hypothermia and intestinal ileus}

Sir,

The metabolic disorders of neonates subject to cold exposure have again been pointed out by Smales and Hull (Archives, 1978, 53, 407) and abnormalities of oxygen consumption and environmental temperature have been shown by Hey (1969).

Since a term infant born unattended at home, was admitted with a core body temperature of $32^{\circ} \mathrm{C}$, we have 